\title{
Human control of climate change
}

\author{
Varun Dutt • Cleotilde Gonzalez
}

Received: 21 June 2009 / Accepted: 27 July 2011

(C) Springer Science+Business Media B.V. 2011

\begin{abstract}
The use of analogies and repeated feedback might help people learn about the dynamics of climate change. In this paper, we study the influence of repeated feedback on the control of a carbon-dioxide $\left(\mathrm{CO}_{2}\right)$ concentration to a goal level in a Dynamic Climate Change Simulator (DCCS) using the "bathtub" analogy. DCCS is a simplification of the complex climate system into its essential elements: $\mathrm{CO}_{2}$ concentration (stock); man-made $\mathrm{CO}_{2}$ emissions (inflow); and natural $\mathrm{CO}_{2}$ removal or absorption in the atmosphere (outflow). In a laboratory experiment involving DCCS, we manipulated feedback delays in two ways: the frequency of emission decisions and the rate of $\mathrm{CO}_{2}$ absorption from the atmosphere (climate dynamics). Our results revealed that participants' ability to control the $\mathrm{CO}_{2}$ concentration generally remained poor even in conditions where they were allowed to revise their emission decisions frequently (i.e., every 2 years) and where the climate dynamics were rapid (i.e., 1.6\% of $\mathrm{CO}_{2}$ concentration was removed every year). Participants' control of the concentration only improved with repeated feedback in conditions of lesser feedback delay. Moreover, the delay due to climate dynamics had a greater effect on participants' control than the delay due to emission decisions frequency. We provide future research directions and highlight the potential of using simulations like DCCS to help people learn about dynamics of Earth's climate.
\end{abstract}

\section{Introduction}

Growing evidence indicates that people do not understand accumulation processes even in simple dynamic systems that include a single stock (or accumulation), a single inflow rate that increases the stock, and a single outflow rate that decreases the stock (Booth Sweeney and Sterman 2000; Cronin and Gonzalez 2007; Cronin et al. 2009; Sterman and Booth Sweeney 2002). In fact, even people with strong background in mathematics and sciences

Electronic supplementary material The online version of this article (doi:10.1007/s10584-011-0202-x) contains supplementary material, which is available to authorized users.

V. Dutt $(\bowtie) \cdot$ C. Gonzalez

Dynamic Decision Making Laboratory, Carnegie Mellon University, 4609 Winthrop Street, Pittsburgh, PA 15213, USA

e-mail: varundutt@cmu.edu

C. Gonzalez

e-mail: coty@cmu.edu 
fail to interpret a basic principle of dynamic systems: a stock rises (or falls) when the inflow exceeds (or is less than) the outflow (Cronin et al. 2009).

Climate is a complex dynamic system that presents important challenges for its perception, interpretation, and understanding by the general public (Bostrom et al. 1994; Moxnes and Saysel 2009; Read et al. 1994; Sterman and Booth Sweeney 2007). It has been shown that people rely upon a simple but erroneous heuristic called the correlation heuristic, whereby they wrongly believe that system outputs are positively correlated with inputs. For the climate system, relying on the correlation heuristic means incorrectly assuming that stabilizing emissions (inputs) would rapidly stabilize greenhouse gas (GHG) concentration (output); and, emissions cuts would quickly reverse GHG concentration (Sterman and Booth Sweeney 2002, 2007). Consequently, people who rely on this heuristic are likely to defer acting on climate change ("wait-and-see" behavior) because they significantly underestimate the delay between reductions in GHG emissions and reductions in GHG concentration (misperceptions of feedback), and the magnitude of emissions reductions needed to stabilize the concentration.

According to the misperceptions of feedback (MOF) hypothesis (Sterman 1989), people ignore the actions in a dynamic system that involves feedback delays. In the case of the climate system, the MOF hypothesis suggests that people likely fail to account for the long time delays between increases in carbon-dioxide $\left(\mathrm{CO}_{2}\right)$ emissions and the subsequent increases in $\mathrm{CO}_{2}$ concentration, and those between increases in $\mathrm{CO}_{2}$ concentration and its effects on increasing atmospheric temperature. An increase in emissions does not increase concentration and atmospheric temperature immediately, but after a long delay where it might be too late to act to avoid significant impact.

Moxnes and Saysel (2009) have built on Sterman and Booth Sweeney's (2007) study by investigating how people regulate $\mathrm{CO}_{2}$ emissions to reach an attainable concentration goal in a simulated climate system. They tested participants' ability to control the concentration to $300 \mathrm{GtC}$ above the pre-industrial level in a period between the years 2000 and 2100 , where participants decided on emissions every 10 years. Participants were tested in different conditions that mimicked the working of the climate system, with repeated feedback about decisions and the resulting changes in $\mathrm{CO}_{2}$ concentration. Participants entered ten numbers which represented their emission decisions every 10 years over a 100 year period. In all but one feedback condition, participants entered all ten emissions at one time and then saw the effects of their decisions. In the conditions without feedback, Moxnes and Saysel's (2009) results coincided with the static, onetime, paper-and-pencil climate policy task's results from Sterman and Booth Sweeney (2007): Participants showed a general tendency to overshoot the goal level and to rely on the correlation heuristic in their emission decisions. In the feedback condition, however, Moxnes and Saysel (2009) gave participants the ability to make repeated emission decisions every 10 years and to observe the effects of these decisions. Within a 10 year period, the emissions remained constant at values which were set at the start of the period. Results showed that providing repeated feedback helped participants change their strategy over time, and may have helped them to reduce their reliance on the correlation heuristic and misperceptions of feedback.

In this paper, we build on prior studies by utilizing an interactive and dynamic stockmanagement simulation (Gonzalez and Dutt 2011). This task, called the Dynamic Climate Change Simulation (DCCS), ${ }^{1}$ is used to investigate people's ability to control $\mathrm{CO}_{2}$ concentration to a goal level under different kinds of feedback delays for inputs $\left(\mathrm{CO}_{2}\right.$

\footnotetext{
${ }^{1}$ The DCCS simulation can be downloaded for free under an academic license from: http://downloads. ddmlab.com/?action=form\&package_id $=2$
} 
emissions) and outputs $\left(\mathrm{CO}_{2}\right.$ removal or $\mathrm{CO}_{2}$ absorptions). Our main objective is to investigate the reasons for participants' poor control over dynamic systems, particularly in the context of climate change, and to discover possibilities in which these problems can be overcome.

The DCCS utilizes the graphical "bathtub metaphor" proposed by Sterman and Booth Sweeney (2007) and expands upon the feedback manipulation presented by Moxnes and Saysel (2009). The bathtub metaphor is a common analogy used to explain the behavior of dynamic systems (Sterman 2000), and it has also been used to communicate the complex dynamics of the climate system (Kunzig 2009). DCCS is different from the simulation used in Moxnes and Saysel (2009) because it is an interactive simulation where participants make emission decisions repeatedly after a certain number of time periods. The emissions, absorption, and concentration information is represented graphically on the DCCS's interface. According to Moxnes and Saysel's (2009) results, one would expect less reliance on the correlation heuristic and MOF, and less wait-and-see behavior given the transparency in DCCS. Furthermore, by manipulating the frequency of feedback, we expect participants to improve their strategy in controlling $\mathrm{CO}_{2}$ concentration more often and over several time periods of interaction with the task (Moxnes and Saysel 2009). However, there are currently several open questions regarding how helpful feedback frequency and the historical information provided in a simulation is to learning control (Moxnes and Saysel 2009).

In general, research is needed to develop interventions to help people learn about the dynamics of climate. Simulation tools like DCCS may help overcome the reliance on MOF and correlation heuristic by giving direct experience with the accumulation processes and feedback delays involved. Research is also needed to compare people's understanding using tools like DCCS in contrast to other forms of information presentation, including descriptive information such as the Intergovernmental Panel on Climate Change (IPCC) reports (Houghton et al. 2001), one-shot climate policy task (Sterman and Booth Sweeney 2007), or simulations with no feedback (Moxnes and Saysel 2009). In this regard, an initial evaluation of DCCS was performed to investigate the effects of repeated feedback on subsequent performance in Sterman and Booth Sweeney's (2007) climate policy task (Dutt and Gonzalez 2010). In that study, we provided participants with experiences of future $\mathrm{CO}_{2}$ concentration in DCCS. One group was first asked to control the concentration in DCCS to a predefined goal trajectory over 100 time periods. This group was later given Sterman and Booth Sweeney's (2007) climate policy task, which asked them to sketch emissions and absorption corresponding to a $\mathrm{CO}_{2}$ concentration trajectory over 100 time periods. A separate group of participants did not experience DCCS and were immediately given the climate policy task. Results showed that participants with experiences in DCCS were able to reduce their reliance on correlation heuristic and MOF in their sketches compared to participants without DCCS experiences. Thus, the repeated feedback in DCCS enabled participants to answer subsequent climate policy task more accurately.

In this paper, we study the effects of two delay types in repeated feedback that are present in emissions and absorption on participants' ability to control the concentration in DCCS. One type of feedback delay is the frequency of emission decisions. Moxnes and Saysel (2009) kept this delay fixed at 10 emission decisions in increments of 10 years each, while we vary the frequency at two levels: high, every 2 years; and low, every 4 years. The second type of feedback delay manipulated is the climate dynamics: variations in the rate of natural $\mathrm{CO}_{2}$ absorption in DCCS. Moxnes and Saysel (2009) also discussed how current uncertainty in our understanding of absorption processes might influence our ability to control the concentration. In this paper, we test this idea by manipulating the climate dynamics in DCCS at two levels: slow, $1.2 \%$ of $\mathrm{CO}_{2}$ concentration per year; and rapid, $1.6 \%$ of $\mathrm{CO}_{2}$ concentration per year. 
These two feedback delays in $\mathrm{CO}_{2}$ emissions (inflow) and $\mathrm{CO}_{2}$ absorption (outflow) are of two very different kinds. The delay due to the frequency of emission decisions is similar to production delay (Diehl and Sterman 1995), but it is feed-forward for climate (i.e., people need to anticipate future emissions that affect $\mathrm{CO}_{2}$ concentration). Thus, what is set as emissions policies now is held constant in DCCS for a certain number of time periods (years) in the future. On the other hand, feedback delay in the climate dynamics determines the speed with which $\mathrm{CO}_{2}$ is absorbed from the atmosphere in each time period. This feedback delay is outside of the participants' direct control, and it is an inherent part of the climate system simulated in DCCS.

In this paper, it is hypothesized that:

H1: In DCCS, slower climate dynamics and less frequent emission decisions would result in poorer human control of the $\mathrm{CO}_{2}$ concentration to a goal level, compared to faster dynamics and more frequent decisions.

This hypothesis is supported by prior evidence of how the MOF hypothesis and feedback delays generally hinder human control in dynamic tasks (Brehmer 1989; Diehl and Sterman 1995; Dörner 1980; Paich and Sterman 1993; Sterman 1989). In addition, both the climate dynamics and frequency of emission decisions have been identified as particularly hard to understand by the general public (Cramer et al. 2001; Joos et al. 2001; Matear and Hirst 1999; Moxnes 2004; Moxnes and Saysel 2009; Sarmiento and Le Quéré 1996; Sterman and Booth Sweeney 2007), though it is hard to determine beforehand which of these two delays would be more problematic in DCCS.

In what follows, we first motivate the development of DCCS and its capabilities. Then, details of an experiment where the two feedback delays were manipulated are provided. Finally, we provide experimental results, and discuss their implications for enabling better understanding of the climate system and future research directions.

\section{A simplified model of the earth's climate}

Figure 1 provides the system-dynamics representation of a simple climate model used in DCCS (for Vensim ${ }^{\circledR}$ PLE model equations refer to the supplementary material). The $\mathrm{CO}_{2}$ Concentration represents the accumulation in the atmosphere which increases indirectly from an inflow of man-made $\mathrm{CO}_{2}$ emissions called Total Emissions (made of two kinds of emissions: fossil-fuel and deforestation). The outflow Absorptions causes a decrease in $\mathrm{CO}_{2}$ Concentration due to $\mathrm{CO}_{2}$ absorbed by terrestrial and oceanic ecosystems. As long as Total

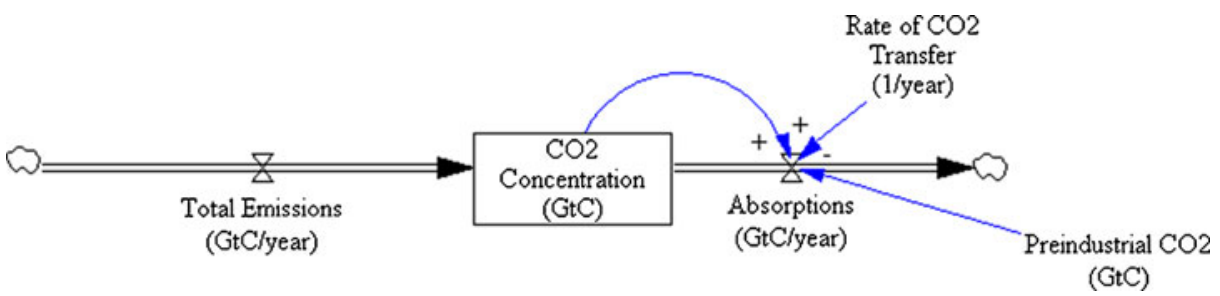

Fig. 1 The simple climate model. The $\mathrm{CO}_{2}$ Concentration represents the stock or accumulation in the atmosphere. The $\mathrm{CO}_{2}$ concentration increases indirectly by man-made (or anthropogenic) Total Emissions (i.e., inflow). The Rate of $\mathrm{CO}_{2}$ Transfer is a constant multiplier into $\mathrm{CO}_{2}$ Concentration that gives rise to Absorptions after the Preindustrial $\mathrm{CO}_{2}$ (the 1970 baseline $\mathrm{CO}_{2}$ concentration) has been subtracted from the $\mathrm{CO}_{2}$ Concentration 
Emissions exceed Absorptions, $\mathrm{CO}_{2}$ Concentration continues to increase. Only when Total Emissions equal Absorptions will $\mathrm{CO}_{2}$ Concentration stabilize at a particular level. The arrow from $\mathrm{CO}_{2}$ Concentration into Absorptions illustrates that the Absorptions are a function of $\mathrm{CO}_{2}$ Concentration at all times and are assumed to be directly proportional to $\mathrm{CO}_{2}$ Concentration.

This model representation is very similar to the example of filling and draining a bathtub (the bathtub metaphor) (Sterman 2000). The Rate of $\mathrm{CO}_{2}$ Transfer in the model is a constant multiplier in $\mathrm{CO}_{2}$ Concentration that gives rise to Absorptions after the Preindustrial $\mathrm{CO}_{2}$ (the 1970 baseline $\mathrm{CO}_{2}$ concentration) has been subtracted from $\mathrm{CO}_{2}$ Concentration (the Preindustrial $\mathrm{CO}_{2}$ concentration is assumed to be due to natural $\mathrm{CO}_{2}$ emissions and equals $677 \mathrm{GtC}$ ). The use of a baseline concentration and year enables us to determine the change in Absorptions values.

The model can be represented mathematically as:

$$
\mathrm{d}\left(\mathrm{CO}_{2} \text { Concentration }\right) / \mathrm{dt}=\mathrm{CO}_{2} \text { Emissions }- \text { Absorptions }
$$

Where Absorptions are defined as:

$$
\text { Absorptions }=\text { Rate of } \mathrm{CO}_{2} \text { transfer } *\left(\mathrm{CO}_{2} \text { Concentration }- \text { Preindustrial } \mathrm{CO}_{2}\right)^{2}
$$

This simple climate model was calibrated between years 2000 and 2100 with projections given by two different and extreme emission scenarios from the 2001 IPCC report (Houghton et al. 2001; Nakicenovic et al. 2000). A popular carbon-dioxide dynamics model, called the Integrated Science Assessment Model (ISAM), was used to predict $\mathrm{CO}_{2}$ Concentration for the two emission scenarios: an "optimistic" and a "pessimistic" scenario (Jain et al. 1994). The scenarios are storylines about potential courses of future emissions. For details on the ISAM model, scenarios, and our calibration exercise, please refer to the supplementary material.

After calibrating our simple climate model with the ISAM model, we found that the Rate of $\mathrm{CO}_{2}$ Transfer was 0.016 of the $\mathrm{CO}_{2}$ concentration per year in the optimistic scenario and 0.012 of the $\mathrm{CO}_{2}$ concentration per year in the pessimistic scenario. The calibration of our model's predictions for $\mathrm{CO}_{2}$ concentration with the ISAM model's predictions is shown in Fig. 2. The top and bottom panels show the calibration in the optimistic and pessimistic scenarios, respectively. For the optimistic scenario, $R^{2}=.97$, $\mathrm{RMSD}=.50 \mathrm{GtC}$ for a Rate of $\mathrm{CO}_{2}$ Transfer $=1.6 \%$ of $\mathrm{CO}_{2}$ concentration. For the pessimistic scenario, $\mathrm{R}^{2}=.99, \mathrm{RMSD}=.50 \mathrm{GtC}$ for a Rate of $\mathrm{CO}_{2}$ Transfer $=1.2 \%$ of $\mathrm{CO}_{2}$ concentration. Therefore, our model closely replicates results from a more mechanistic ISAM model and represents realistic predictions of future $\mathrm{CO}_{2}$ concentration based upon those two Rates of $\mathrm{CO}_{2}$ Transfer.

Those two Rates of $\mathrm{CO}_{2}$ Transfer were used to manipulate the feedback delay due to climate dynamics. Later, we used this model as the scientific basis to design DCCS.

\footnotetext{
${ }^{2}$ The units of $\mathrm{CO}_{2}$ Concentration are $\mathrm{GtC}$ (Giga or $10^{9}$ tons of carbon) and represent the $\mathrm{CO}_{2}$ concentration in the atmosphere above its preindustrial level. The units of Total Emissions and Absorptions are GtC per year (Giga tons of carbon per year). The Rate of $\mathrm{CO}_{2}$ Transfer is the amount of $\mathrm{CO}_{2}$ absorbed in a single year with units of percentage (\%) per year. The inverse of the Rate of $\mathrm{CO}_{2}$ Transfer yields the average residence time of $\mathrm{CO}_{2}$ in the atmosphere. As a cautious reader would have observed, the Rate of $\mathrm{CO}_{2}$ Transfer is assumed to be a constant for the model.
} 


\section{Climate Model Fit to ISAM Model for Optimistic Scenario}
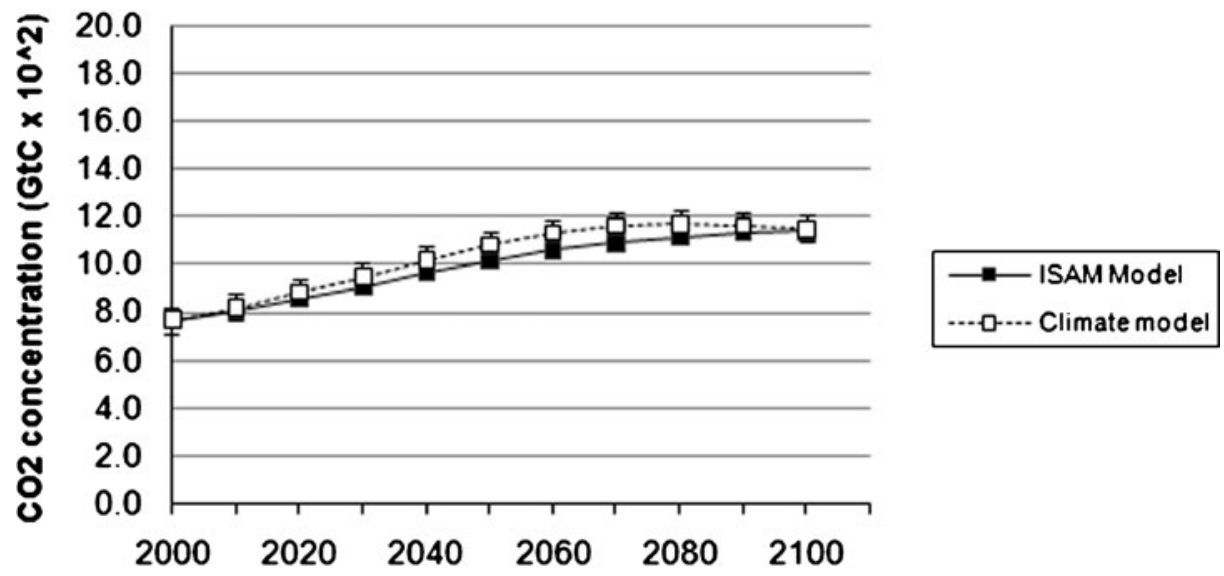

\section{Climate Model Fit to ISAM Model for Pessimistic Scenario}
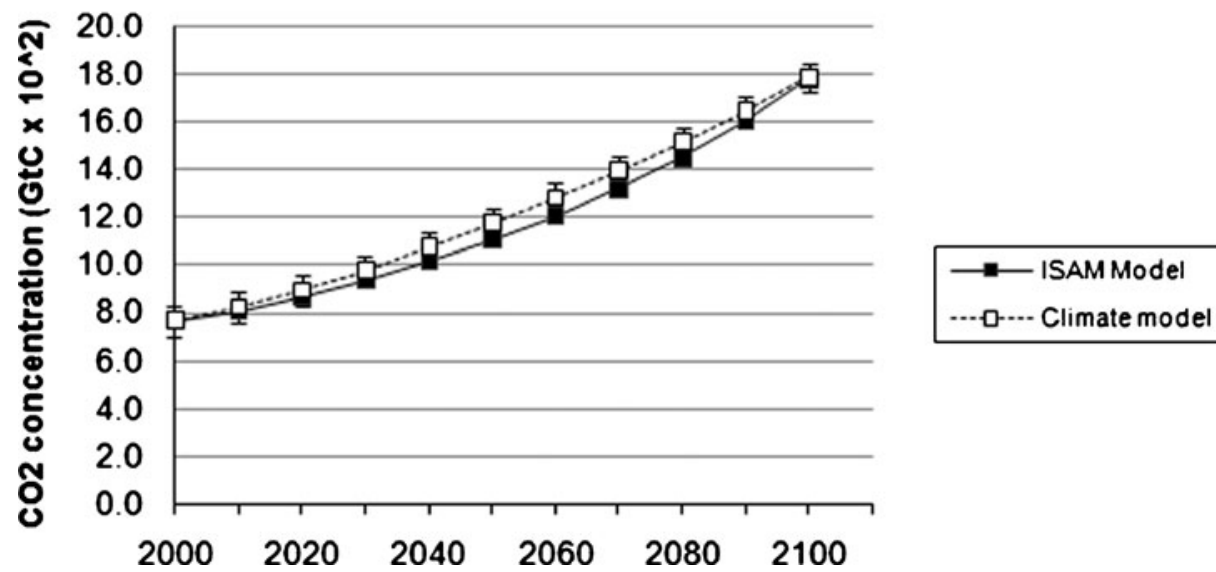

Fig. 2 Top panel: The simple climate model calibrated to ISAM model's predictions in the optimistic scenario, $\mathrm{R}^{2}=.97, \mathrm{RMSD}=.50$, Rate of $\mathrm{CO}_{2}$ Transfer $=0.016$. Bottom panel: The simple climate model calibrated to ISAM model's predictions in the pessimistic scenario, $\mathrm{R}^{2}=.99, \mathrm{RMSD}=.50$, Rate of $\mathrm{CO}_{2}$ Transfer $=0.012$. In both figures, error bars show $90 \%$ confidence interval around the average estimate

\section{Dynamic climate change simulator (DCCS)}

DCCS was built on the simple climate model described above, and was inspired by a generic dynamic stock and flows task (Gonzalez and Dutt 2011) and ideas from an earlier study by Moxnes and Saysel (2009). The interface, shown in Fig. 3, presents a single stock, $\mathrm{CO}_{2}$ concentration, as an orange-colored liquid in a tank which metaphorically represents Earth's atmosphere (Fig. 3.1). The participants' aim is to maintain the $\mathrm{CO}_{2}$ concentration within an acceptable range around an attainable goal level of $938 \mathrm{GtC}$ ( $=450 \mathrm{ppmv}$ ). The level is shown with a green horizontal line labeled Goal. Participants are asked to keep the 


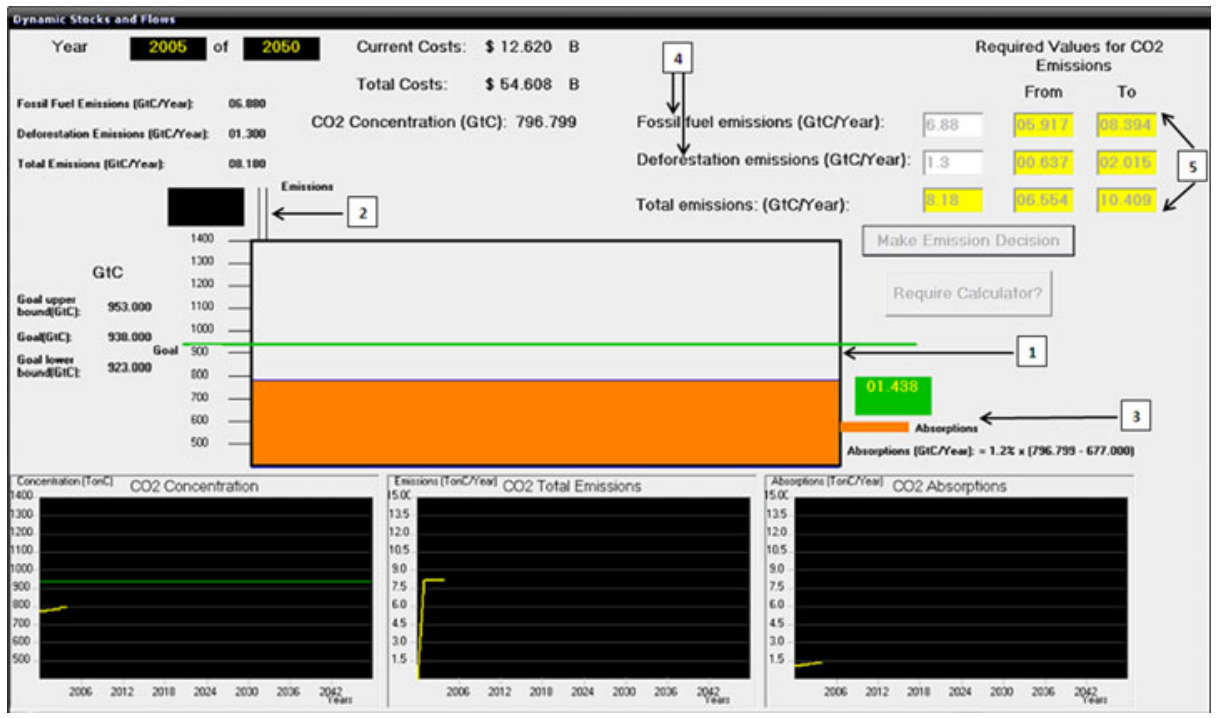

Fig. 3 Dynamic Climate Change Simulator (DCCS) task (see description in text)

concentration within +/-15 GtC of the goal level (Goal upper bound (GtC) and Goal lower bound $(G t C)$ define the upper and lower bounds of this range). The current time period's $\mathrm{CO}_{2}$ Concentration is presented on the y-axis, and it is also displayed as a label above the tank.

In the 1992 Dynamic Integrated Climate Economy model (or DICE-92; Nordhaus 1992) and in the real world, there are two major man-made sources of $\mathrm{CO}_{2}$ emissions: from deforestation and land use, and from burning fossil-fuels, especially in transportation, power generation, and industry. In DCCS, participants decide on both emission types (Fig. 3.4). These two emissions are summed, and their addition represents the Total Emissions represented on the interface by a pipe connecting the top-left of the tank (Fig. 3.2). Based upon the IPCC report (Houghton et al. 2001), the starting proportions of fossil-fuel emissions in Total Emissions is $80 \%$ and starting deforestation emissions constitute only $20 \%$. Below the Year range, information on the last time period's Fossil Fuel Emissions (GtC/Year), Deforestation Emissions (GtC/Year), and Total Emissions (GtC/Year) is displayed.

Absorptions, represented by a pipe on the bottom right of the tank (Fig. 3.3), are proportional to $\mathrm{CO}_{2}$ concentration and decrease the concentration according to our simple climate model. The absorption equation and its values are also shown on the interface (see Fig. 3).

Participants set emissions in the boxes respectively labeled Fossil fuel emissions ( $\mathrm{GtC}$ ) year) and Deforestation emissions (GtC/year), and then click the Make Emission Decision button. This causes DCCS to implement these emissions as Total Emissions and to provide feedback on the $\mathrm{CO}_{2}$ concentration resulting from Total Emissions and Absorptions.

To avoid extreme exploration in participants' emission decisions, the fossil-fuel and deforestation emissions are restricted to the values between the From and To ranges (Fig. 3.5). These ranges provide realistic bounds on the possible increases and decreases in emissions, and reflect realistic emission policies in the real world. The From value ensures that emissions reductions do not underestimate world economic growth and energy 
requirements. At the same time, the To value allows for economic growth and a more fossilfuel intensive economy. The From value does not allow participants to cut their yearly emissions immediately, while the $T o$ value allows participants to increase their yearly emissions by only certain amounts. The values in these ranges are dynamic and are calculated after each emission decision is executed. The From and To range for fossil-fuel emissions was set at $-14 \%$ to $+22 \%$ of the value of its current emissions. For deforestation emissions, the From and To range was set at $-51 \%$ to $+55 \%$ of its current emissions. The exact values were derived after analyzing the maximum and minimum values of current and future emissions across different emission scenarios (Jain et al. 1994). To see how these ranges were determined, please refer to the supplementary material of the paper.

There are three graphical displays provided at the bottom of DCCS's interface. The display on the left shows the current and past $\mathrm{CO}_{2}$ concentrations across several time periods up to the current time point in the simulation (the simulation year is shown in the top-left corner of the interface). Displays in the middle and on the right show the current and past total $\mathrm{CO}_{2}$ emissions and $\mathrm{CO}_{2}$ absorptions, respectively.

In DCCS, each time a participant is unable to keep the concentration within the goal range, she incurs a cost penalty based upon the IPCC report (Houghton et al. 2001). The penalty (in \$) represents damages due to climate change in the time participants take to control the $\mathrm{CO}_{2}$ concentration to the goal. It is assumed to be $\$ 100$ million per GtC times the difference between the goal and the current $\mathrm{CO}_{2}$ concentration (in $\mathrm{GtC}$ ). Participants do not incur this penalty if they maintain the concentration within the permissible range around the goal. Current and accumulated penalties are shown as the Current Costs and Total Costs.

After participants enter their emissions values and click Make Emission Decision, DCCS automatically moves forward by a number of simulated years. During each of the transit years until DCCS stops again, Total Emissions are maintained at the same constant values initially entered. This procedure is similar to establishing an emission policy that is kept constant for a number of planned years. After that number of years, participants can again decide on new values for emissions based upon the current and past $\mathrm{CO}_{2}$ concentrations. This repeated decision-feedback process carries on until the final year is reached.

\section{Experiment}

When emission decisions are made less frequently, there is a larger gap between two consecutive decisions. Due to the MOF hypothesis and feedback delay in emission decisions, poorer performance in DCCS is expected when decisions are less frequent compared to when they are more frequent.

Different climate dynamics were induced by taking two Rates of $\mathrm{CO}_{2}$ Transfer values, which result in different $\mathrm{CO}_{2}$ absorptions in DCCS (Eq. 2). We used a $1.6 \%$ per year rate (optimistic scenario, rapid dynamics) and a $1.2 \%$ per year rate (pessimistic scenario, slow dynamics). When climate dynamics are slow, the feedback delay in DCCS increases and poorer performance is expected compared to a situation where the climate dynamics are rapid.

Although any kind of feedback delay is expected to produce sub-optimal control over the $\mathrm{CO}_{2}$ concentration, this experiment helps us determine which of these two feedback delays produces a more detrimental effect and how they interact to determine how people learn about climate dynamics under different dynamic conditions. These feedback delays are important representations of the actual delays in man-made emission decisions and in the real world climate system (where the latter is beyond the direct human control). For 
example, climate meetings and negotiations (i.e., the frequency of emission decisions) have become nearly annual events since $1996 .^{3}$

Also, it is expected that oceans (Matear and Hirst 1999; Sarmiento and Le Quéré 1996) and plants would reduce their ability to absorb $\mathrm{CO}_{2}$ due to the increases in $\mathrm{CO}_{2}$ concentration (Cramer et al. 2001; Joos et al. 2001). Therefore, it is important to consider the variations in climate dynamics and its effects on human learning.

As mentioned, the climate dynamics combined with the frequency of emission decisions is expected to hamper human learning and result in increased difficulties in the control of $\mathrm{CO}_{2}$ concentration in DCCS. Specifically, a situation with slower climate dynamics (i.e., $1.2 \%$ rate of $\mathrm{CO}_{2}$ transfer) combined with less frequent emission decisions (i.e., every 4 years) is expected to result in the poorest performance. Due to these long feedback delays involved, participants who are unable to foresee the long-term effects of their decisions are likely to show overshooting and undershooting in their attempts to reach the goal level. It is also likely that only a smaller proportion of participants are able to reach and stabilize the $\mathrm{CO}_{2}$ concentration within the goal range, and that they would need more time periods to do so. This oscillatory (sinusoidal) behavior in $\mathrm{CO}_{2}$ concentration trajectory over time is similar to that observed in other complex dynamic control systems (Forrester 1961; Sterman 1989). In contrast, higher frequency of emission decisions (i.e., every 2 years) combined with rapid climate dynamics (i.e., $1.6 \%$ rate of $\mathrm{CO}_{2}$ transfer) is expected to result in the best control of the concentration in DCCS.

\section{Methods}

\subsection{Experimental design}

Participants were randomly assigned to one of four between-subjects conditions: rapidhigh, where the rate of $\mathrm{CO}_{2}$ transfer is $1.6 \%$ per year with emission decisions made every 2 simulated years; rapid-low, where the rate of $\mathrm{CO}_{2}$ transfer is $1.6 \%$ per year with emission decisions made every 4 simulated years; slow-high, where the rate of $\mathrm{CO}_{2}$ transfer is $1.2 \%$ per year with emission decisions made every 2 years; and slow-low, where the rate of transfer is $1.2 \%$ per year with $\mathrm{CO}_{2}$ emission decisions made every 4 years.

Participants' target under all four conditions was to maintain the $\mathrm{CO}_{2}$ concentration within a $+/-15 \mathrm{GtC}$ range around a $938 \mathrm{GtC}(\sim 450 \mathrm{ppmv})$ goal value. In order to equalize the number of decisions made in all four conditions to 50 decisions each, the high conditions ran for 100 simulated years and the low conditions for 200 years. The DCCS started in the year 2000 where the initial $\mathrm{CO}_{2}$ concentration was fixed at $769 \mathrm{GtC}$, the realworld value of $\mathrm{CO}_{2}$ concentration that year (Houghton et al. 2001). Similarly, the initial deforestation emissions were fixed at $1.3 \mathrm{GtC} /$ year and the initial fossil-fuel emissions at $6.88 \mathrm{GtC} /$ year (Houghton et al. 2001).

The value of the $\mathrm{CO}_{2}$ concentration goal $(=938 \mathrm{GtC})$ was deliberately set above 2000 's $\mathrm{CO}_{2}$ concentration $(=769 \mathrm{GtC} \sim 370 \mathrm{ppmv}$ ). That is because attainable goals in the real-world are set higher than the status-quo concentration with an expectation that emission reductions will be immediately initiated to attain these goals. In addition, the goal used in our experiment corresponds to the IPCC's "best-case" stabilization scenario (Houghton et al. 2001, pg. 76). Goal values that are higher than year 2000's actual concentration were also used by Moxnes

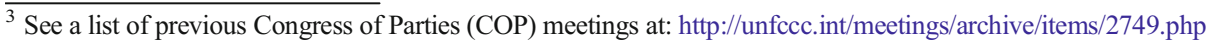


and Saysel (2009). Setting the goal higher than the status-quo concentration is also necessary to make the goal realistically achievable and to account for the practical inability to drastically reduce emissions. In addition, a participant may try to increase emissions initially. Again, this increase mimics the pattern of real-world emissions, which are accelerating (see CSIRO Australia, December 8, 2006 for more details). The main implication of achieving the goal in our experiment is to attain control over the $\mathrm{CO}_{2}$ concentration to levels that are considered safe for Earth's climate. Thus, participants who manage to do so do not incur any costly penalties. The more time participants take to reach and maintain the concentration within the goal range, the more it will cost them.

Across all conditions, the $\mathrm{CO}_{2}$ concentration will stabilize at the goal when total emissions equal $\mathrm{CO}_{2}$ absorption. This means that when climate dynamics are slow, the optimal value of total emissions should equal $(938-677) * 0.012=3.13 \mathrm{GtC}$ per year. Similarly, when climate dynamics are rapid, the optimal value of total emissions should equal $(938-677) * 0.016=4.18 \mathrm{GtC}$ per year (Eq. 2).

The optimal combination of emission values was calculated to reach the goal in the minimum number of time periods for each condition. These values are irrespective of the frequency of emission decisions. Therefore, if a participant is able to decrease total emissions from the initial value of $8.18 \mathrm{GtC}$ per year to the corresponding optimal values, then that participant would be able to optimally hit the goal and stabilize the concentration at the goal.

We use the absolute value of the discrepancy as the main dependent variable (absolute discrepancy measures the deviation from a goal and equals the absolute value of the difference between the goal and $\mathrm{CO}_{2}$ concentration). Also, we used fossil-fuel, deforestation, and total emissions as other dependent variables to investigate participants' decision-making strategies in a regression model.

\subsection{Participants}

Fifty-three graduate and undergraduate students from diverse fields of study participated in this experiment, 26 were females. Ages ranged from 18 years to 54 years (Mean=26 years, $\mathrm{SD}=8$ years). In self-reports, $64 \%$ of participants indicated having heard of climate change through television, websites, or movies; $25 \%$ reported having read something about climate change through newspapers or magazines; and the remaining $11 \%$ reported having knowledge on the subject through some other means. Also, $70 \%$ of participants either reported having completed or currently pursuing degrees in science, technology, engineering, and management (STEM).

Fourteen participants were randomly assigned to the slow-low condition and thirteen participants were assigned to each of the slow-high, rapid-high, and rapid-low conditions, respectively. All participants received a base pay of $\$ 5$ for a 30-minute study. Participants could also earn an additional bonus of no more than $\$ 3$, which was based on their performance in DCCS. If a participant deviated outside the goal range in any given time period, then a cost penalty was incurred that was calculated as the product of $\$ 100$ million and the absolute discrepancy in that time period. Participants incurring more than $\$ 400$ billion in accumulated costs were paid a bonus of $\$ 0$. Participants incurring less than or equal to $\$ 15$ billion in accumulated costs were paid a bonus of $\$ 3$. All other accumulated costs between $\$ 15$ billion and $\$ 400$ billion were linearly transformed to actual dollar payments. Four hundred billion dollars is four times the accumulated cost incurred if one entered the optimal values for total emissions for the slow climate dynamics. Therefore, the upper limit on the penalty was not very stringent and still enabled them to explore and learn from their decisions and repeated feedback. Similarly, a $\$ 15$ billion lower bound was 
kept to ensure that the initial discrepancy between the concentration and the goal range's lower bound in the starting year did not penalize participants.

\subsection{Procedure}

Participants were given instructions before starting the DCCS task. The instructional text given in the slow-low condition is provided in the supplementary material. After participants read the instructions, they were shown a video of what would happen in DCCS if the status-quo total emissions $(=8.18 \mathrm{GtC})$ were maintained for the next 50 years. Climate dynamics in this video were set at their manipulated value of $1.2 \%$ or $1.6 \%$ of the $\mathrm{CO}_{2}$ concentration per year depending upon the condition. The main intention was to motivate participants and to make them understand what would happen if they maintained the status quo emissions for the next 50 years. Starting in the year 2000, the video's $\mathrm{CO}_{2}$ concentration crossed the $938 \mathrm{GtC}$ goal value and increased to more than $1000 \mathrm{GtC}$ by the year 2050, which is more than a 5\% increase from 2000's value. After watching the video, participants were asked to imagine the severe consequences this increase would have on the world's climate. Participants only watched the video and did not interact with DCCS at this point. In addition, 2000's fossil-fuel and deforestation emissions values were used throughout the demonstration and the same video was shown to all participants in all conditions. Showing the video could possibly anchor and bias participants' judgments. But this bias does not constitute a problem in the experiment because believing that $\mathrm{CO}_{2}$ emissions need to change or fall does not necessarily help people understand when and by how much these emissions need to be reduced.

After the video, participants were reminded of the requirements in DCCS. They were then asked to play DCCS for 50 decision points over a course of 100 or 200 years depending upon the condition.

\section{Results}

\subsection{General performance: Discrepancy from goal}

Figure 4 shows the average absolute discrepancy in each condition (the absolute discrepancy is averaged over all participants and decision points in a condition). Participants were clearly not performing optimally. The average absolute discrepancy is greater than the optimal goal range (the black line showing "Optimal" is the upper bound at $15 \mathrm{GtC}$ of the goal range) in all conditions. The distribution of discrepancies in all four conditions was non-normal. Normality of the dependent variable in our data was tested for on the 1 st, 25 th, and 50 th decision points in all four conditions. ${ }^{4}$

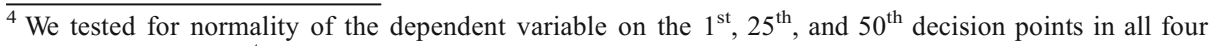
conditions. For the $1^{\text {st }}$ decision point, the data was normal in the rapid-high and slow-high conditions, $D$ $(13)=.913, n s$ and $D(13)=.930, n s$, respectively; however, it was non-normal for the slow-low and rapidlow conditions, $D(14)=.776, p<.05$ and $D(13)=.862, p<.05$, respectively. For the $25^{\text {th }}$ decision point, the data was normal for the rapid-high and slow-high conditions, $D(13)=.887$, ns and $D(13)=.924, n s$, respectively; however, it was non-normal for the slow-low and rapid-low conditions, $D(14)=.606, p<.05$ and $D(13)=.819, p<.05$, respectively. Lastly, for the $50^{\text {th }}$ decision point, the data was non-normal in all conditions, i.e., rapid-high $(D(13)=.655, p<.05)$, slow-high $(D(13)=.650, p<.05)$, slow-low $(D(14)=.819, p<.05)$, and rapid-low $(D(13)=.627, p<.05)$, respectively.
} 


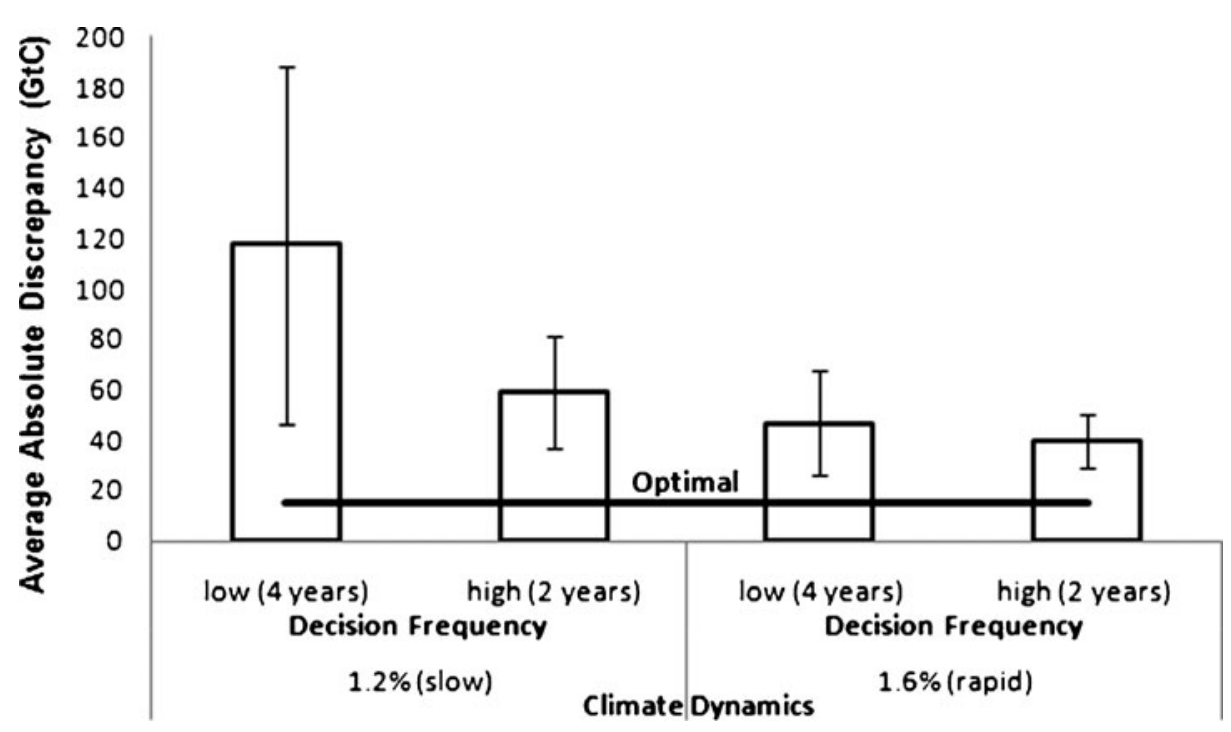

Fig. 4 Average Absolute Discrepancy $(\mathrm{GtC})$ in the four conditions (this discrepancy is averaged over all participants and decisions points in a condition). Participants have more difficulty achieving control of $\mathrm{CO}_{2}$ concentration when climate dynamics are slow than rapid and when the frequency of emission decisions is low than high. Error bars show 90\% confidence interval around the average estimate. The line labeled "Optimal" shows the optimal value around the goal of $15 \mathrm{GtC}$ (if participants kept their Average Absolute Discrepancy within the goal range then they should be below the optimal). Absolute Discrepancy was more than the "Optimal" value in all conditions. Readers wanting to convert the result to ppmv can use a $0.47 \mathrm{ppmv}$ to $1 \mathrm{GtC}$ conversion ratio

Levene's test for homogeneity of variances for the dependent variable revealed that the variance in the data were non-homogenous at those points, $F(3,49)=2.668, p<.05 ; F(3,49)=$ $7.561, p<.05$ and $F(3,49)=10.136, p<.05$, respectively.

A nonparametric Kruskal-Wallis test reported that the effect of different conditions on the absolute value of the discrepancy was significant $(H(3)=12.120, p<.05)$. In fact, the average absolute discrepancy was greater when the emission decisions frequency was low (Median= $61.77 \mathrm{GtC}$ ) compared to when it was high (Median=45.57 GtC), $U=267.00, Z=-3.00, p<.01$, $r=-.21$. In addition, the average absolute discrepancy was greater when climate dynamics were slow (Median=61.67 GtC) compared to when they were rapid (Median=37.42 GtC), $U=$ $182.00, Z=-3.00, p<.01, r=-.41$. Thus, the hypothesis is supported: participants' control of the $\mathrm{CO}_{2}$ concentration is poorer when the climate dynamics were slow and the emission decisions were made less frequently compared to when the climate dynamics were rapid and the emission decisions were made more frequently.

Post-hoc pair-wise comparisons for the average absolute discrepancy revealed the following: slow-low condition (Median=79.40 GtC) $>$ rapid-high condition (Median=40.34 GtC), $U=26.00, Z=-3.154, p<.01, r=-.43$; slow-high (Median=52.78 GtC) was no different from rapid-low (Median=32.74 GtC), $U=64.00, Z=-1.051, n s, r=-.14$; rapid-high (Median= $40.34 \mathrm{GtC}$ ) was no different from rapid-low (Median=32.74 GtC), $U=83.00, Z=-0.077, n s$, $r=-.01$; slow-low (Median=79.40 GtC) $>$ slow-high (Median=52.78 GtC), $U=53.00$, $Z=-3.000, p<.01, \quad r=-.25$; slow-low (Median=79.40 GtC) $>$ rapid-low (Median=32.74 $\mathrm{GtC}), U=37.00, Z=-2.620, p<.01, r=-.36$; and rapid-high (Median=40.34 GtC) was no different from slow-high (Median=52.78 GtC), $U=55.00, Z=-1.513, n s, r=-.21$. 


\subsection{Learning effects}

Figure 5 shows the average absolute discrepancy in each of the four conditions over 50 decision points (each point within each condition is averaged over all participants in that condition). As expected, the discrepancy in the slow-low condition shows a sinusoid oscillation above the optimal value across all 50 decision points. In addition, according to the confidence intervals, the slow-low condition has the greatest variability in human behavior.

In each of the four conditions, the average absolute discrepancy changed significantly over 50 decision points according to a nonparametric Friedman's ANOVA test $\left(\chi^{2}(49)=\right.$ $371.02, p<.001 ; \chi^{2}(49)=230.51, p<.001 ; \chi^{2}(49)=296.17, p<.001 ;$ and $\chi^{2}(49)=97.40$, $p<.001$ for the rapid-high, rapid-low, slow-high, and slow-low conditions, respectively). There was no difference in the average absolute discrepancy between the 1st decision point $($ Median $=163.27 \mathrm{GtC})$ and the 50th decision point (Median=59.32 GtC) in the slow-low condition, $T=23, p>.05, r=-.35$. In contrast, this difference was significant in the other three conditions. The average absolute discrepancy in the rapid-high, slow-high, and rapidlow conditions was significantly greater for the 1st decision point (Median=161.57 GtC; Median=163.04 GtC; and Median=162.80 GtC respectively) compared to the 50th decision point (Median=5.66 GtC; Median=8.24 GtC; and Median=11.97 GtC), with, $T=0, p<.001, r=-.62 ; T=1, p<.001, r=-.61$ and $T=0, p<.001, r=-.62$, respectively. These results suggest that the repeated feedback in DCCS enabled participants to learn about the dynamics of the simulated climate system in all conditions but slow-low. In the slow-low condition, learning is offset by the presence of strong oscillations in discrepancy due to excessive feedback delays. These results also demonstrate DCCS' effectiveness in helping participants learn how to stabilize their $\mathrm{CO}_{2}$ concentration in three out of the four conditions; however, these three conditions are those that have comparatively less feedback delay than the slow-low condition.

\subsection{Participants' strategies}

\subsubsection{Reaching and stabilizing within the goal range}

The time it took participants' $\mathrm{CO}_{2}$ concentration to reach the goal range for the first time and their ability to keep it within the goal range thereafter were analyzed. The proportion of participants that reached the goal range for the first time was smaller when climate dynamics were slow (Mean $=78 \%$ ) compared to when they were rapid (Mean=96\%), $U=286.50$, $Z=-1.97, p<.05, r=-.27$. The frequency of emission decisions had no effect on the proportion of participants reaching the goal. Furthermore, we classified participants as "stabilizing at the goal," if their $\mathrm{CO}_{2}$ concentration was maintained within the goal range for eight consecutive time periods after it initially came within the goal range. The proportion of participants stabilizing at the goal was significantly smaller when climate dynamics were slow (Mean= $41 \%$ ) compared to when they were rapid (Mean=65\%), $U=286.00, Z=-1.97, p<.05, r=-.27$. Again, frequency of emission decisions had no effect on the proportion of participants stabilizing at the goal. These results suggest that human control behavior is significantly driven by the climate dynamics and less so by the frequency of emission decisions.

\subsubsection{Ratio of fossil-fuel to total emissions}

To understand participants' choices between the two emission types, the ratio of fossil-fuel emissions to total emissions was analyzed. Fossil-fuel emissions constituted 

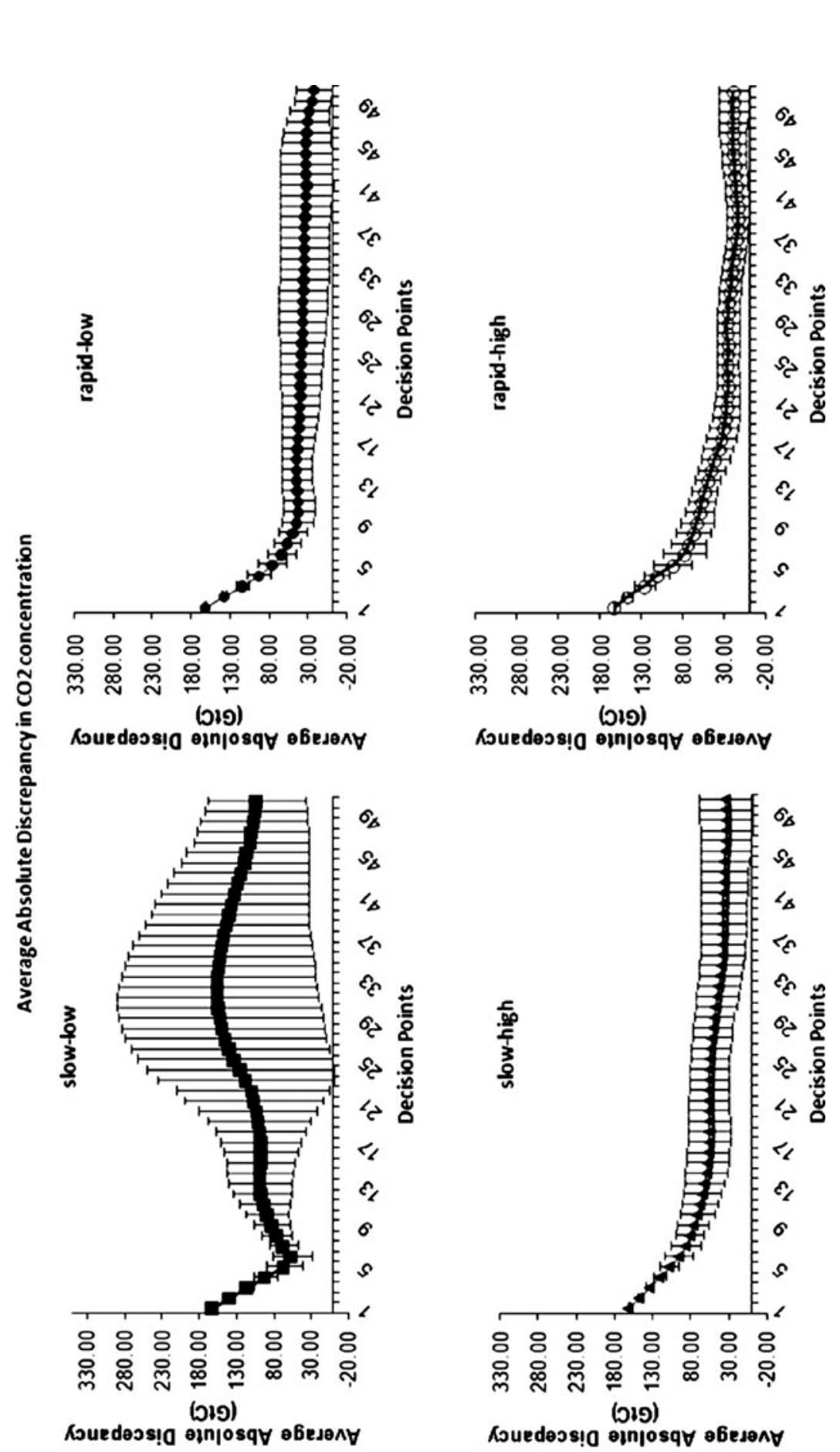

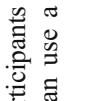

ㅇㅇㅇㅇㅇㅇㅇㅇㅇ

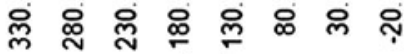

Kourdess!o olnjosq

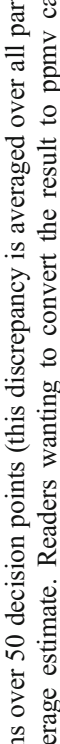

ำ

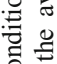

을

핼 을

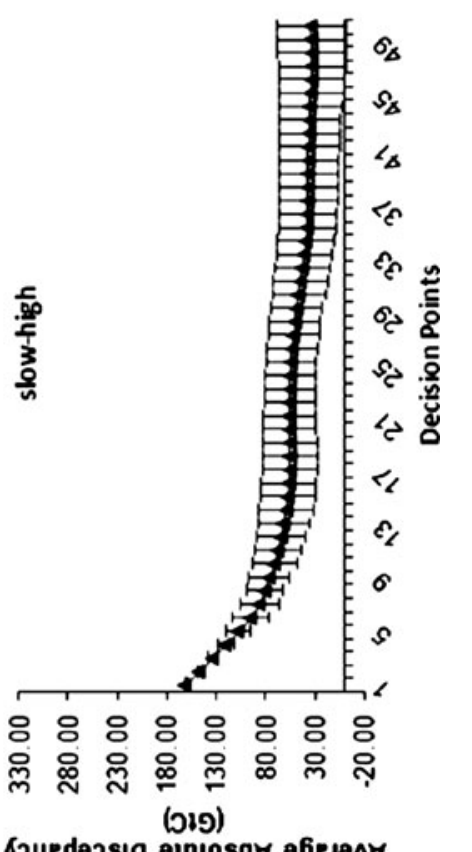

Кэueders! 0 อ!กjosq 
on average $96 \%$ of total emissions and deforestation emissions only the remaining $4 \%$. However, these percentages did not change significantly as a function of different conditions. These results indicate that participants chose fossil-fuel emissions as the primary means of controlling their $\mathrm{CO}_{2}$ concentration over the deforestation emissions overall.

\subsubsection{Distance of emissions from TO value}

A reason for greater discrepancy in conditions of greater feedback delay might be that participants maintain the fossil-fuel and deforestation emissions closer to the $T o$ value in the range of emissions. When emissions are closer to the $T o$ side of the range, it also indicates participants' attempt to increase emissions faster. An analysis of fossil-fuel and deforestation emissions' distances to the $T o$ value revealed that fossil-fuel emissions were on average only $36 \%$ away from the $T o$ value and the deforestation emissions were on average only $42 \%$ away. Therefore, participants generally kept emissions closer to the $T o$ values. Furthermore, this strategy for the two emission types varied with condition (fossil-fuel emissions: $H(3)=12.044, p<.01$; deforestation emissions: $H(3)=7.800, p<.05$ ). Fossil-fuel and deforestation emissions were significantly closer to the $T o$ value when climate dynamics were slow (Median $=28 \%$; Median $=25 \%$ ) compared to when they were rapid (Median= $45 \%$; Median=38\%), $U=168.00, Z=-3.26, p<.001, r=-.45$ and $U=206.00, Z=-2.58$, $p<.01, r=-.35$, respectively. Again, the frequency of emission decisions did not influence the distance to the $T o$ value.

Detailed comparisons show that both emissions were significantly closer to the $T o$ value in the slow-low condition (Median=25\%, Median=26\%) compared to the rapid-high condition (Median=38\%, Median=48\%), $U=32.00, Z=-2.692, p<.01, r=-.52$ and $U=$ $33.00, Z=-2.641, p<.01, r=-.52$, respectively. Thus, these results show that participants kept emissions closer to the To value of the From - To range in conditions of longer feedback delay.

\subsection{Decision rule: Emission decisions}

Similar to other stock-management problems (Sterman 1989), the decision rule used to determine $\mathrm{CO}_{2}$ emissions can be adapted to the DCCS task: emissions are a function of $\mathrm{CO}_{2}$ concentration and $\mathrm{CO}_{2}$ absorption. We developed three regression models to predict each of the following: the average Total Emissions (TE), the average Fossil-fuel Emissions (FE), and the average Deforestation Emissions (DE).

Predictor variables were calculated as the average of the 50 decision points for each participant. This gave a dataset of 53 data points (one point for each participant) for the purpose of three multiple regression models with the following predictors:

A

$D$

$F E_{\text {from }}$

$F E_{\text {to }}$

$D E_{\text {from }}$

$D E_{t o}$

Ratio $_{\text {FossilToTotal }}$

DistanceFossil $_{\text {from }}$

DistanceDeforestation $_{\text {from }}$
$\mathrm{CO}_{2}$ absorption

Discrepancy (Goal - Amount)

Fossil-fuel emissions' From Value

Fossil-fuel emissions' To Value

Deforestation emissions' From Value

Deforestation emissions' To Value

Ratio of fossil-fuel emissions to Total emissions

Distance of fossil-fuel emissions from the From value

Distance of deforestation emissions from the From value 
In addition, we kept two dummy $\{0,1\}$ variables to test for the effects of different conditions:

$F R \quad$ Frequency of emission decisions ( $F R=1$ for low, i.e., every 4 years; $F R=0$ for high, i.e., every 2 years)

$C D$ Climate Dynamics $\left(C D=1\right.$ for slow, i.e., $1.2 \%$ of $\mathrm{CO}_{2}$ concentration; $C D=0$ for rapid, i.e., $1.6 \%$ of $\mathrm{CO}_{2}$ concentration)

$e \quad$ Residual

The following equations were used in each of the three models:

Model 1

$$
\begin{aligned}
\mathrm{FE}= & \mathrm{b}_{0}+\mathrm{b}_{1} \mathrm{D}+\mathrm{b}_{2} \mathrm{~A}+\mathrm{b}_{3} \mathrm{FE}_{\text {from }}+\mathrm{b}_{4} \mathrm{FE}_{\mathrm{to}}+\mathrm{b}_{5} \text { Ratio }_{\text {FossilToTotal }} \\
& +\mathrm{b}_{6} \text { DistanceFossil }_{\text {from }}+\mathrm{b}_{7} \mathrm{CD}+\mathrm{b}_{8} \mathrm{FR}+\mathrm{e}
\end{aligned}
$$

Model 2

$$
\begin{aligned}
\mathrm{DE}= & \mathrm{b}_{0}+\mathrm{b}_{1} \mathrm{D}+\mathrm{b}_{2} \mathrm{~A}+\mathrm{b}_{3} \mathrm{DE}_{\text {from }}+\mathrm{b}_{4} \mathrm{DE}_{\mathrm{to}}+\mathrm{b}_{5} \text { Ratio FossilToTotal } \\
& +\mathrm{b}_{6} \text { DistanceDeforestation }_{\text {from }}+\mathrm{b}_{7} \mathrm{CD}+\mathrm{b}_{8} \mathrm{FR}+\mathrm{e}
\end{aligned}
$$

Model 3

$$
\begin{aligned}
\mathrm{TE}= & \mathrm{b}_{0}+\mathrm{b}_{1} \mathrm{D}+\mathrm{b}_{2} \mathrm{~A}+\mathrm{b}_{3} \mathrm{FE}_{\text {from }}+\mathrm{b}_{4} \mathrm{FE}_{\mathrm{to}}+\mathrm{b}_{5} \mathrm{DE}_{\text {from }}+\mathrm{b}_{6} \mathrm{DE}_{\mathrm{to}} \\
& +\mathrm{b}_{7} \text { Ratio }_{\text {FossilToTotal }}+\mathrm{b}_{8} \text { DistanceFossil }_{\text {from }}+\mathrm{b}_{9} \text { DistanceDeforestation }_{\text {from }} \\
& +\mathrm{b}_{10} \mathrm{CD}+\mathrm{b}_{11} \mathrm{FR}+\mathrm{e}
\end{aligned}
$$

When $C D=0$ and $F R=0$, the three resulting models generate predictions for the rapidhigh condition, which is the condition with the least feedback delay and best participants' performance. Therefore, values of the standardized beta coefficients $\left(b_{x}\right)$ in these models are relative to the rapid-high condition.

Table 1 provides the results of ordinary least-squares linear regression involving these models.

As seen in Table 1 , model $1(p<.001)$ accounted for $92.7 \%$ of the variance in fossil-fuel emissions. The only standardized beta coefficients that were significant were the From and To ranges for fossil-fuel emissions. Both of these standardized beta coefficients also possessed strong positive values, i.e., an increase in the From or To predictors caused an increase in fossil-fuel emissions while holding all other predictors constant. Participants did take the values of the From and To ranges into account while making their fossil-fuel emissions, and moreover the ranges caused participants to increase fossil-fuel emissions.

Model $2(p<.001)$ accounted for $92.9 \%$ of the variance in the deforestation emissions. Similar to Model 1, the standardized beta coefficients of the From and To ranges for 


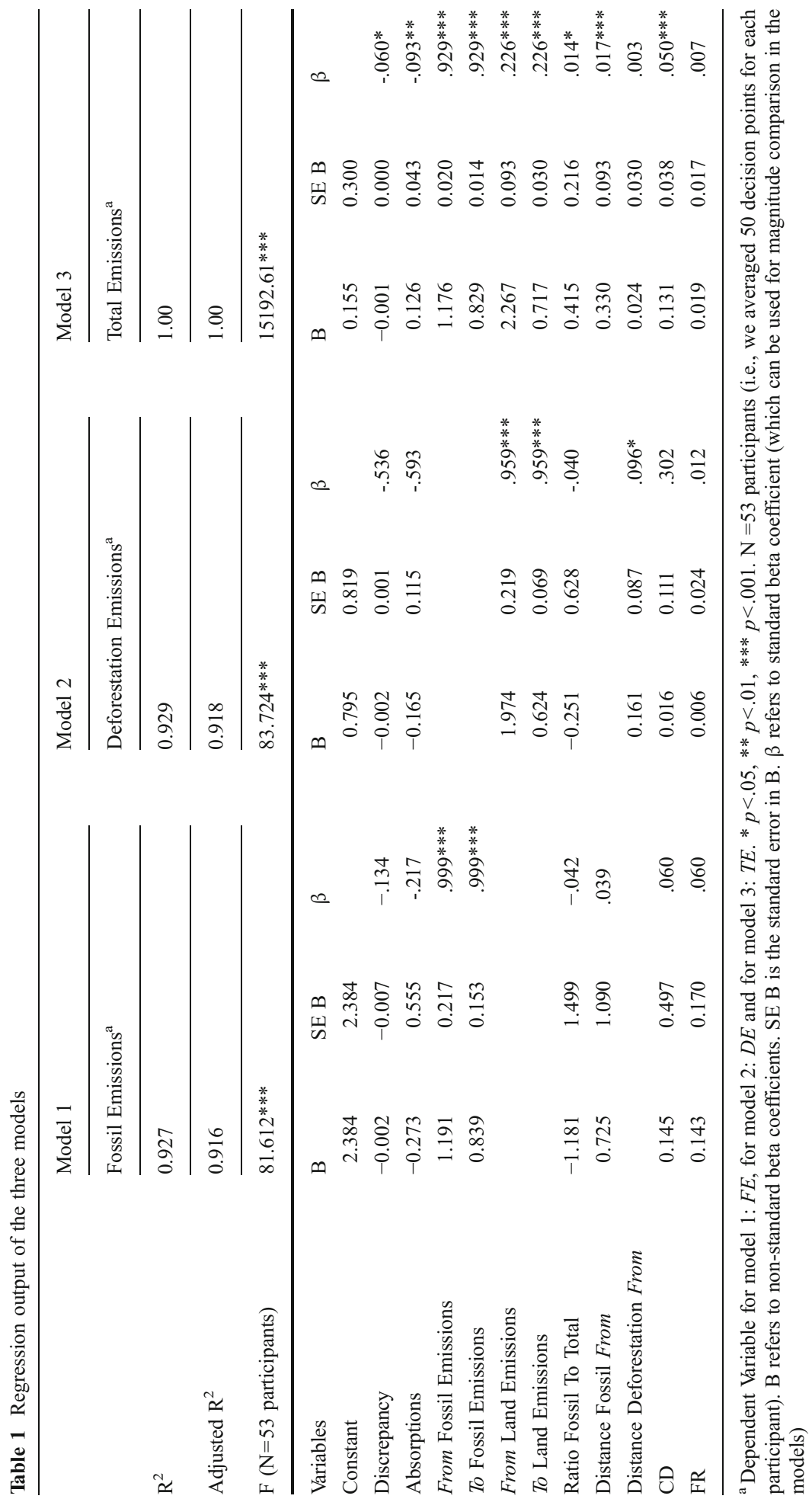


deforestation emissions were significant and positive. The standardized beta coefficient of the distance of deforestation emissions from the From value was also significant and positive. These findings are consistent with the reasoning that participants who maintained their deforestation emissions father away from the From value, or kept them closer to the To value, were bound to cause significant increases in their deforestation emissions.

Model $3(p<.001)$ accounts for $100 \%$ of the variance in total emissions. Firstly, the standardized beta coefficients of Discrepancy and $\mathrm{CO}_{2}$ absorption predictors were negative and significantly affected total emissions. As per our simple climate model, $\mathrm{CO}_{2}$ absorption is proportional to the concentration and thus also proportional to the discrepancy. In addition, participants in DCCS need to decrease emissions from a higher value to make it equal to absorption in order to control $\mathrm{CO}_{2}$ concentration (the absorption were less than total emissions initially in the year 2000). Due to the same reason, the correlation between total emissions and $\mathrm{CO}_{2}$ absorption should be negative if participants were able to control the concentration within the goal range. The decrease in total emissions on account of an increase in Discrepancy and absorption predictors indicates that participants decreased their total emissions from the greater initial year 2000 value in different conditions. Participants do learn to control the $\mathrm{CO}_{2}$ concentration over repeated time periods as they decrease their total emissions when their Discrepancy predictor increases.

In addition, consistent with the previous two regression models, the standardized beta coefficients of the From and To ranges in model 3 for both emission types significantly affected the total emissions. The effect of the From and To ranges for fossil-fuel emissions on the total emissions (beta coefficient $=.929$ ) exceeded that of the From and To ranges for deforestation emissions (beta coefficient $=.226$ ) when all other predictors were maintained at their constant values.

Furthermore, the standardized beta coefficients for the Ratio FossiltoTotal and DistanceFossil $_{\text {From }}$ predictors were positive and significantly affected total emissions. The effect of these two predictors on total emissions validates earlier findings that participants predominantly used fossil-fuel emissions to control the $\mathrm{CO}_{2}$ concentration. Finally, climate dynamics (determined by $C D$ dummy) significantly affected the total emissions. This observation is also consistent with the earlier finding where the discrepancy and therefore $\mathrm{CO}_{2}$ concentration resulting from total emissions was greater with slower climate dynamics (as shown in Fig. 4). The frequency of emission decisions did not influence total emissions. Furthermore, the magnitude of standardized beta coefficient for emission decisions frequency ( $F R$ dummy) was less than the standardized beta coefficient for climate dynamics ( $C D$ dummy variable). The significance and magnitude of the standardized beta coefficients for the $C D$ and $F R$ dummy variables show that climate dynamics played a significantly greater role compared to decision frequency when comparing their individual effects on total emissions.

\section{Discussions and conclusions}

Many of the complex dynamic effects found in the real world can be better understood with simple tasks (Cronin et al. 2009), and a demonstration of such a process for a simulated climate system was presented here in DCCS. The complex problem was simplified into its essential elements: $\mathrm{CO}_{2}$ concentration, and $\mathrm{CO}_{2}$ emissions and absorptions over time. DCCS was built from a simple climate model, and it was used to investigate participants' ability to control the system under different conditions of feedback delays: frequency of emission decisions and climate dynamics. Results show that a change in climate dynamics 
from rapid to slow (when averaged across the frequency of emission decisions) deteriorated participants' control of $\mathrm{CO}_{2}$ concentration compared to a change in frequency of emission decisions from high to low (when averaged across the climate dynamics). This supports many previous results on people's inability to understand basic dynamics and to control an accumulation in the presence of feedback delays (Brehmer 1989; Diehl and Sterman 1995; Dörner 1980; Gonzalez 2005; Sterman 1989). Despite the poor performance, participants improved their control over the $\mathrm{CO}_{2}$ concentration over many time periods in DCCS for three out of the four conditions. These three conditions are those where the feedback delay was the least.

Emission decisions frequency results are consistent with previous findings in a simulated climate system (Moxnes and Saysel 2009) and in other dynamic systems (Diehl and Sterman 1995; Paich and Sterman 1993). Participants' control performance deteriorates as a function of increasing delays in the inflow and outflow. The effects created by delays in our study are similar to the cause-and-effect relationships that determine the fate of the population in Dörner and Kimber's (1997) study, where participants had to increase the well-being of fictitious occupants in the presence of long feedback delays between their decision actions and outcomes.

Furthermore, we find evidence of the MOF hypothesis in our results on account of the oscillatory behavior found in $\mathrm{CO}_{2}$ concentration for the slow-low condition. In this study, participants started below the goal and were asked to stabilize the concentration within the goal range as quickly as possible. These requirements caused participants to rapidly increase emissions in the initial period of performance to bring their concentrations closer to the goal as quickly as possible. However, participants soon realized that their $\mathrm{CO}_{2}$ emissions were too high to stabilize the concentration and thus their concentration trajectories tended to overshoot the goal range.

We argue that participants' poor control is likely due to their failure to reduce $\mathrm{CO}_{2}$ emissions in DCCS. To be successful in this task, participants need to slowly reduce emissions, but instead we found their emissions to be closer to the $T o$ value of emissions range. The late realization that emissions are too high when participants reach the goal range produces an attempt to reduce emissions when it is already too late (the coefficients of absorptions and discrepancy in regression model 3 were negative, showing that overall participants do try to reduce total emissions on account of these two predictors). This late correction causes a "bullwhip" sinusoidal oscillation, which is well known in dynamic systems with feedback delays (Sterman 1989) and a sign of the MOF. One possible explanation for the greater effect of climate dynamics is the saliency and nature of the feedback delay in emission decisions. Fossil-fuel and deforestation emissions are directly controlled and manipulated by participants in all conditions from one decision point to the next. Repeatedly making emission decisions and observing their effects might force participants to notice the delay present in their direct controls. Furthermore, repeatedly making decisions enables participants to anticipate the future effects of emissions. This explanation is supported by the fact that prior research has found similar effects for repeated feedback and how it improves performance in a control task similar to DCCS (Dutt and Gonzalez 2008a, 2008b).

Participants' control only improved in those conditions that offered comparatively less feedback delays. In future research, we plan to investigate learning over many repeated performances in DCCS. Prior work in dynamic decision making literature suggests that participants' initial performance in interactive management flight simulators is generally quite poor, but they can improve due to repeated performances (Brehmer 1989; Diehl and Sterman 1995; Dörner and Kimber 1997; Sterman, 1989). This finding of learning-by- 
doing is intuitive, and it is one of the strengths of management flight simulators that we could test for in DCCS in the future. In the current experiment, participants faced the same conditions in a single performance and thus, may have improved solely as a function of repetition, without developing any generic understanding about accumulation or how to handle time delays. Following the work of Diehl and Sterman (1995) and Paich and Sterman (1993), we would like to vary the learning parameters in DCCS from one performance to the next without revealing these variations to participants. This manipulation is likely a better test of participants' understanding of the principles of accumulation. For example, we would like to vary key parameters such as the climate dynamics and then asses participants' knowledge of the relevant processes (i.e., the stockflow structure, controlling atmospheric $\mathrm{CO}_{2}$ concentrations, the impact of feedback from $\mathrm{CO}_{2}$ concentrations, etc.) using a pre-test and post-test design. As part of the pre- and posttest, participants' knowledge may be tested outside the context of the simulator by using Sterman and Booth Sweeney's (2007) climate policy task.

Management flight simulators are becoming increasingly common and may be used by the IPCC to supplement its forthcoming assessment reports. ${ }^{5}$ Currently, in the real world, people are more likely to be exposed to traditional descriptive text and figures that describe the projected impacts of different climate policies. Here, people must make judgments about when and by how much emissions must decline to meet any goal for either the $\mathrm{CO}_{2}$ concentration or temperature change (such as stabilizing at $\mathrm{CO}_{2}$ at $450 \mathrm{ppmv}$ or with warming $\leq 2{ }^{\circ} \mathrm{C}$ ). Because prior research shows that people cannot make such judgments reliably, one would like to know if the chance to explore these dynamics through a simulator might help them better understand these issues in common settings. These settings might include reading media reports or other information about future climate change, and the policy options to control it. As mentioned above, Dutt and Gonzalez (2010) have found DCCS to be effective in helping people to understand the dynamics of $\mathrm{CO}_{2}$ concentration. A group of participants, who experienced DCCS, performed better in the succeeding Sterman and Booth Sweeney's (2007) climate policy task compared to another group of participants who performed the climate policy task directly. As part of future research, we would also like to know what features of simulations are most helpful in building people's understanding of climatic processes - as the examples above illustrate, existing simulators vary widely in their level of detail in regards to the carbon cycle, other greenhouse gases, radiative forcing, and other climate processes in their interface designs, use of graphics and video, and in many other attributes. Therefore, it might be interesting to evaluate what features enable the most effective learning. A future study centered on investigating a simulator's greatest features would make a vitally needed contribution to our understanding of the critical processes in risk communication for climate change and other issues involving complex dynamic systems.

Acknowledgements This research was partially supported by the National Science Foundation; Human and Social Dynamics: Decision, Risk, and Uncertainty, award number: 0624228, to Cleotilde Gonzalez. We would like to thank Hau-yu Wong, Dynamic Decision Making Laboratory for her editorial comments on this paper. Furthermore, we would like to thank the faculty at the department of Engineering and Public Policy at Carnegie Mellon University who gave us helpful comments on previous versions of this paper.

\footnotetext{
${ }^{5}$ For example: http://climateinterative.org; http://scripts.mit.edu/ jsterman/climate/master/; http://www.astr. ucl.ac.be/users/matthews/jcm/; and http:/www.google.com/landing/cop15/
} 


\section{References}

Booth Sweeney L, Sterman JD (2000) Bathtub dynamics: initial results of a systems thinking inventory. Syst Dyn Rev 16(4):249-294

Bostrom A, Morgan MG, Fischhoff B, Read D (1994) What do people know about global climate change? Part 1: Mental models. Risk Anal 14(6):959-970

Brehmer B (1989) Feedback delays and control in complex dynamic system. In: Milling PM, Zahn EKO (eds) Computer based management of complex systems. Springer, Berlin, pp 189-196

Cramer W, Bondeau A, Woodward FI, Prentice C, Betts RA, Brovkin V et al (2001) Global response of terrestrial ecosystem structure and function to $\mathrm{CO}_{2}$ and climate change: Results from six dynamic global vegetation models. Glob Ch Biol 7:357-373

Cronin M, Gonzalez C (2007) Understanding the building blocks of system dynamics. Syst Dyn Rev 23(1):1-17

Cronin M, Gonzalez C, Sterman JD (2009) Why don't well-educated adults understand accumulation? A challenge to researchers, educators and citizens. Organ Behav Hum Decis Process 108(1):116-130

CSIRO Australia (2006) Increase in carbon dioxide emissions accelerating, Australian Research Shows. ScienceDaily, December 8

Diehl E, Sterman JD (1995) Effects of feedback complexity on dynamic decision making. Organ Behav Hum Decis Process 62(2):198-215

Dörner D (1980) On the difficulties people have in dealing with complexity. Simul and Games 11(1):87-106

Dörner D, Kimber R (1997) The logic of failure: recognizing and avoiding error in complex situations. Basic Books, Cambridge

Dutt V, Gonzalez C (2008a) Instance and strategy based models in ACT-R. In: Proceedings of 2008 Modeling, Simulation \& Gaming (MS\&G) Student Capstone Conference, Suffolk, VA, p19

Dutt V, Gonzalez C (2008b) Instance and strategy ACT-R models of choice in a dynamic control task: A model comparison story. In: Proceedings of 2008 Fifteenth Annual Workshop and Summer School by ACT-R RESEARCH GROUP. Pittsburgh, PA, p43

Dutt V, Gonzalez C (2010) Decisions from experience reduces "wait-and-see” behavior in climate change. Manuscript submitted for publication

Forrester JW (1961) Industrial dynamics. Pegasus Communications, Waltham

Gonzalez C (2005) Decision support for real-time dynamic decision making tasks. Organ Behav Hum Decis Process 96:142-154

Gonzalez C, Dutt V (2011) A generic dynamic control task for behavioral research and education. Manuscript accepted for publication in Comp in Hum Behav

Houghton J, Ding Y, Griggs D, Noguer M, van der Linden P, Dai X, Maskell K, Johnson C (eds) (2001) Climate change 2001: The scientific basis. Cambridge University Press, Cambridge

Jain AK, Kheshgi HS, Wuebbles DJ (1994) Integrated science model for assessment of climate change. In: Proceedings of the 87th Annual Meeting and Exhibition of the Air \& Waste Management Association. Cincinnati, Ohio, 94-TP59.08

Joos F, Prentice IC, Sitch S, Meyer R, Hooss G, Plattner GK, Gerber S, Hasselmann K (2001) Global warming feedbacks on terrestrial carbon uptake under the Intergovernmental Panel on Climate Change (IPCC) emission scenarios. Glob Biogeochem Cycles 15(4):891-907

Kunzig R (2009) The carbon bathtub. Article available on "National Geographic" website, http://ngm. nationalgeographic.com/big-idea/05/carbon-bath. December

Matear RJ, Hirst AC (1999) Climate change feedback on the future oceanic $\mathrm{CO}_{2}$ uptake. Tellus 51B:722-733

Moxnes E (2004) Misperceptions of basic dynamics: The case of renewable resource management. Syst Dyn Rev 20(2):139-162

Moxnes E, Saysel AK (2009) Misperceptions of global climate change: information policies. Clim Chang 93:15-37

Nakicenovic N, Alcamo J, Davis G, de Vries B, Fenhann J, Gaffin S, Gregory K, Grubler A, Jung TY, Kram T, La Rovere EL, Michaelis L, Mori S, Morita T, Pepper W, Pitcher H, Price L, Riahi K, Roehrl A, Rogner H-H, Sankovski A, Schlesinger M, Shukla P, Smith S, Swart R, van Rooijen S, Victor N, Dadi Z (2000) Intergovernmental Panel on Climate Change special report on emissions scenarios. Cambridge University Press, Cambridge

Nordhaus WD (1992) The "DICE" model: Background and structure of a dynamic integrated climate economy model of economics of global warming. Cowles Foundation Discussion Paper No. 1009, Cowles Foundation for Research in Economics at Yale University, New Haven, CT

Paich M, Sterman JD (1993) Boom, bust, and failures to learn in experimental markets. Manag Sci 39 (12):1439-1458

Read D, Bostrom A, Morgan MG, Fischhoff B, Smuts D (1994) What do people know about global climate change? Part 2: Survey studies of educated laypeople. Risk Anal 14(6):971-982 
Sarmiento JL, Le Quéré C (1996) Oceanic carbon dioxide uptake in a model of century-scale global warming. Science 274:1346-1350

Sterman JD (1989) Misperceptions of feedback in dynamic decision making. Organ Behav Hum Decis Process 43(3):301-335

Sterman JD (2000) Learning in and about complex systems. Reflections ( $\mathrm{J}$ of the Soc for Organ Learn) 1 (3):24-51

Sterman JD, Booth Sweeney L (2002) Cloudy skies: Assessing public understanding of global warming. Syst Dyn Rev 18(2):207-240

Sterman JD, Booth Sweeney L (2007) Understanding public complacency about climate change: Adults' mental models of climate change violate conservation of matter. Clim Chang 80(3-4):213-238 